\title{
Ortodontia pré-protética e terapia bioprogressiva de Ricketts: relato de casos
}

Pre-prosthetic orthodontics and Ricketts bioprogressive therapy: cases report

Ortodoncia preprotésica y terapia bioprogresiva de Ricketts: reporte de casos

\author{
Artênio José Ísper GARBIN ${ }^{1}$ \\ Bruno WAKAYAMA ${ }^{2}$ \\ Julia Arruda BATISTA ${ }^{1}$ \\ Tania Adas SALIBA ${ }^{2}$
}

${ }^{I}$ Universidade Estadual Paulista (UNESP), Faculdade de Odontologia, Araçatuba. Professor(a) Associado(a) do Departamento de Odontologia Preventiva e Restauradora ${ }^{2}$ Universidade Estadual Paulista (UNESP), Faculdade de Odontologia, Araçatuba. Doutorando(a) do Programa de Pós-graduação em Odontologia Infantil e Social.

\section{Resumo}

Atualmente tem se discutido a importância do planejamento multidisciplinar no tratamento reabilitador do paciente. Neste sentido, a abordagem do tratamento ortodôntico, pregresso a uma reabilitação oral com implantes dentários e próteses são questões que devem ser esclarecidos para o melhor prognóstico do paciente. O objetivo deste estudo foi relatar dois casos clínicos de intervenções ortodônticas préprotéticas baseada na filosofia bioprogressiva de Ricketts, e discutir sua importância frente às possibilidades funcionais e estéticas reabilitadoras. Os casos relatados referem-se a pacientes com perdas de dentes anteriores e/ou posteriores que foram encaminhados ao tratamento ortodôntico pré-protético. Nas três situações, os pacientes faziam uso de próteses parciais removíveis. Baseado nisso, e em consonância à filosofia de bioprogressiva pela individualização do tratamento com movimentos biológicos, leves e controlados, foram incluídos nessas estruturas protéticas tornos expansores e retentores palatinos como artifícios para a mecanoterapia. Os protocolos instituídos foram as ativações dos tornos inicialmente nas consultas mensais, e posteriormente, a cada quinze dias pelos pacientes. Após a expansão adquirida, foram colados os braquetes nos demais dentes, e instaurado mecânica fixa para nivelamento, alinhamento e correção das posições dentárias. Neste momento foram utilizados o Arco Base Inferior, bem como outras alças para movimentações dentárias, baseado nos princípios da bioprogressiva. Conclui-se que a filosofia de Ricketts no tratamento prévio à reabilitação oral mostrou-se eficaz e indicativo. Além disso, ressalta-se que o tratamento ortodôntico pré protético é de grande relevância para a devolução da estética e função do sistema estomatognático do paciente.

Descritores: Ortodontia; Reabilitação Bucal; Má Oclusão; Movimentação Dentária.

\section{Abstract}

Currently, the importance of multidisciplinary planning in the rehabilitation of the patient has been discussed. In this sense, the approach to orthodontic treatment, prior to an oral rehabilitation with dental implants and prostheses are issues that must be clarified for the best prognosis of the patient. The aim of this study was to report two clinical cases of pre-prosthetic orthodontic interventions based on Ricketts' bioprogressive philosophy, and to discuss their importance in view of the functional and aesthetic rehabilitation possibilities. The reported cases refer to patients with loss of anterior and / or posterior teeth who were referred to pre-prosthetic orthodontic treatment. In the three situations, patients used removable partial dentures. Based on this, and in line with the bioprogressive philosophy for the individualization of treatment with biological, light and controlled movements, these prosthetic structures included palatine expanders and retainers as devices for mechanotherapy. The protocols instituted were the activation of the lathes initially in the monthly consultations, and later, every fifteen days by the patients. After the acquired expansion, brackets were glued to the other teeth, and fixed mechanics were installed to level, align and correct dental positions. At this time, the Lower Base Arch was used, as well as other loops for dental movements, based on the principles of bioprogressive. It is concluded that Ricketts' philosophy in the treatment prior to oral rehabilitation proved to be effective and indicative. In addition, it is emphasized that pre-prosthetic orthodontic treatment is of great relevance for the return of aesthetics and function of the patient's stomatognathic system

Descriptors: Orthodontics; Mouth Rehabilitation; Malocclusion; Tooth Movement.

\section{Resumen}

Actualmente, se ha discutido la importancia de la planificación multidisciplinaria en la rehabilitación del paciente. En este sentido, el enfoque del tratamiento de ortodoncia, antes de una rehabilitación oral con implantes dentales y prótesis, son cuestiones que deben aclararse para el mejor pronóstico del paciente. El objetivo de este estudio fue informar dos casos clínicos de intervenciones de ortodoncia preprotésicas basadas en la filosofía bioprogresiva de Ricketts, y discutir su importancia en vista de las posibilidades de rehabilitación funcional y estética. Los casos informados se refieren a pacientes con pérdida de dientes anteriores y / o posteriores que fueron derivados a un tratamiento de ortodoncia preprotésico. En las tres situaciones, los pacientes utilizaron prótesis parciales removibles. En base a esto, y en línea con la filosofía bioprogresiva para la individualización del tratamiento con movimientos biológicos, ligeros y controlados, estas estructuras protésicas incluían expansores y retenedores palatinos como dispositivos para la mecanoterapia. Los protocolos instituidos fueron la activación de los tornos inicialmente en las consultas mensuales, y luego, cada quince días por parte de los pacientes. Después de la expansión adquirida, los brackets se pegaron a los otros dientes, y se instalaron mecánicos fijos para nivelar, alinear y corregir las posiciones dentales. En este momento, se utilizó el arco de la base inferior, así como otros bucles para movimientos dentales, basados en los principios de bioprogresivo. Se concluye que la filosofía de Ricketts en el tratamiento previo a la rehabilitación oral demostró ser efectiva e indicativa. Además, se enfatiza que el tratamiento de ortodoncia preprotésico es de gran relevancia para el retorno de la estética y la función del sistema estomatognático del paciente.

Descriptores: Ortodoncia; Rehabilitación Bucal; Maloclusión; Movimiento Dental.

INTRODUÇÃO

Atualmente, o culto à beleza tem sido amplamente discutido e requerido pelos pacientes, que cada vez mais buscam tratamentos odontológicos que harmonizem face e sorriso, reforçando sua autoestima $^{1,2}$. Neste sentido, a significância dos dentes e sorriso são altamente impactantes nas relações dos indivíduos, pois seu padrão estético está associado diretamente ao julgamento da sua condição de jovialidade, prestígio, influência e acesso ao mercado de trabalho ${ }^{3-5}$.
Na busca pela harmonia dos dentes e do padrão facial, ressalta-se a importância da ortodontia, que além de atuar sobre a estética, possibilita a intervenção dos problemas dentários, ósseos e funcionais $^{6}$. A ortodontia no campo da odontologia, além de promover qualidade de vida em razão da correção das posições dentárias, é a principal especialidade requerida previamente ao tratamento reabilitador, quando há perda ou ausências de elementos dentários, espaços insuficientes para 
instalação de implantes e peças protéticas, posições dentoalveolares discrepantes e más oclusões transversais, verticais e horizontais ${ }^{7}$.

Neste contexto, ressalta-se a importância do planejamento multidisciplinar no tratamento reabilitador do paciente. Para tanto é necessário considerar a queixa principal do paciente, objetivo do tratamento, limitações dos casos, custo benefício, e assim poder indicar de forma coerente e responsável a intervenção das outras áreas da odontologia baseada na real necessidade do indivíduo ${ }^{8,9}$.

Além disso, a escolha do tipo de intervenção ortodôntica a ser empregada deve ser um fator a ser questionado previamente à condução clínica, pois em razão das diversas filosofias de tratamentos existentes, há de se ponderar as indicações, vantagens e limitações das técnicas para melhor aproveitamento das abordagens mecânicas e terapêuticas. Baseada nesta premissa, a filosofia bioprogressiva de Ricketts torna-se eletiva nas intervenções pré-protéticas, visto as possibilidades e grandes recursos existentes para tratamentos individualizados, com movimentações dentárias segmentandas, com alto controle de torque e ancoragem ${ }^{10,11}$.

Ao considerar que com a facilitação do acesso da população ao tratamento odontológico, aumento da expectativa de vida, e valoração sociocultural dos dentes e sorriso, houve maior interesse dos pacientes na busca da reabilitação do sistema estomatognático. Dessa forma, o objetivo do estudo foi relatar dois casos clínicos de intervenção ortodôntica pré-protética baseada na filosofia bioprogressiva de Ricketts, e discutir a importância da ortodontia frente às possibilidades funcionais $\mathrm{e}$ estéticas reabilitadoras.

\section{CASO CLÍNICO}

\section{- Caso Clínico 1}

Paciente do sexo masculino, 47 anos, foi encaminhado pelo implantodontista para tratamento ortodôntico prévio à reabilitação, para distribuição de espaço para a instalação de implantes e peças protéticas. No exame intrabucal, observa-se o arco superior atresico; presença de mordida cruzada posterior do lado esquerdo; dentes topo a topo, ausência dos dentes 16, 21, 22 e 36; restaurações extensas de amalgama e resina; e dentes girovertidos, desalinhados e desnivelados (Figuras 1 a 5).

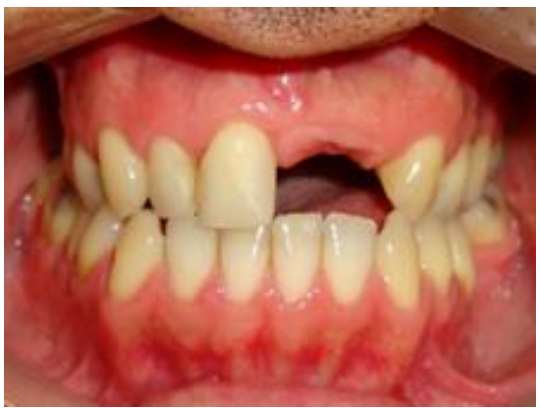

Figura 1: Foto inicial intrabucal frontal.

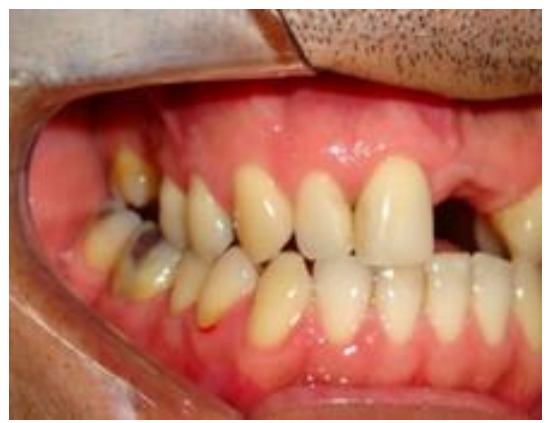

Figura 2: Foto inicial intrabucal lateral direita.

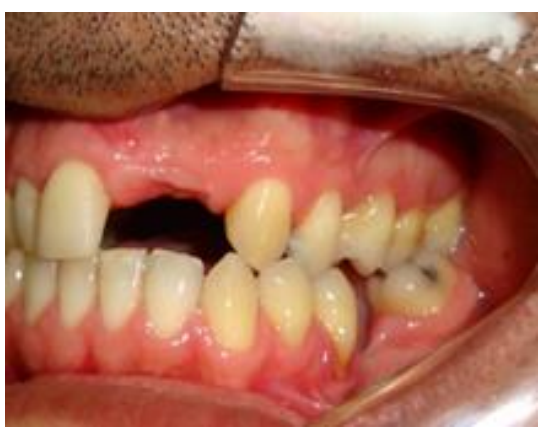

Figura 3: Foto inicial intrabucal lateral esquerda.

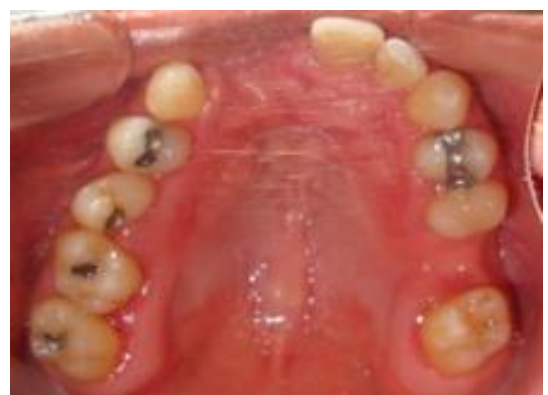

Figura 4: Foto inicial oclusal superior.

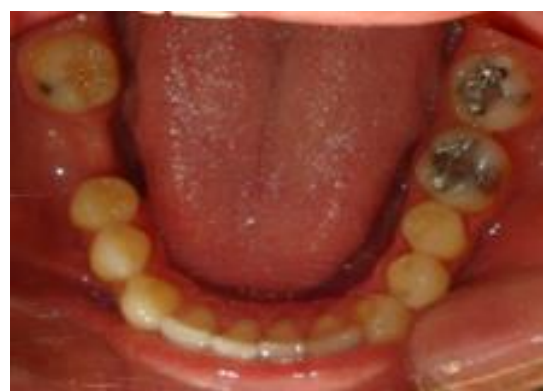

Figura 5: Foto inicial oclusal inferior.

A mecânica instituída para este caso clínico, foi baseada nos princípios da filosofia bioprogressia de Ricketts, que pauta na individualização do planejamento e tratamento do paciente, considerando suas necessidades e limitações. Além disso, essa mecanoterapia torna-se indicativa para intervenções pré protéticas, por utilizarem forças leves e controladas, com movimentos biológicos, respeitando o potencial fisiológico de cada indivíduo.

Dessa forma, devido as várias ausências dentárias, e pelo paciente já utilizar uma prótese parcial removível (PPR) superior, foi incluída nessa estrutura metálica protética, um torno expansor e retentor palatino em resina acrílica (Figuras 6 e 7).

Com o uso da PPR associado a inclusão dos artifícios ortodônticos, foi possível conduzir o tratamento de maneira efetiva, sem afetar a estética e 
função do paciente. Esse recurso mecanoterapêutico foi indicativo e vantajoso para este caso, em razão da dificuldade de se instalar aparelhos ortodônticos fixos na região palatina, como o quadrihélice, para a correção da má oclusão do sentido transversal.
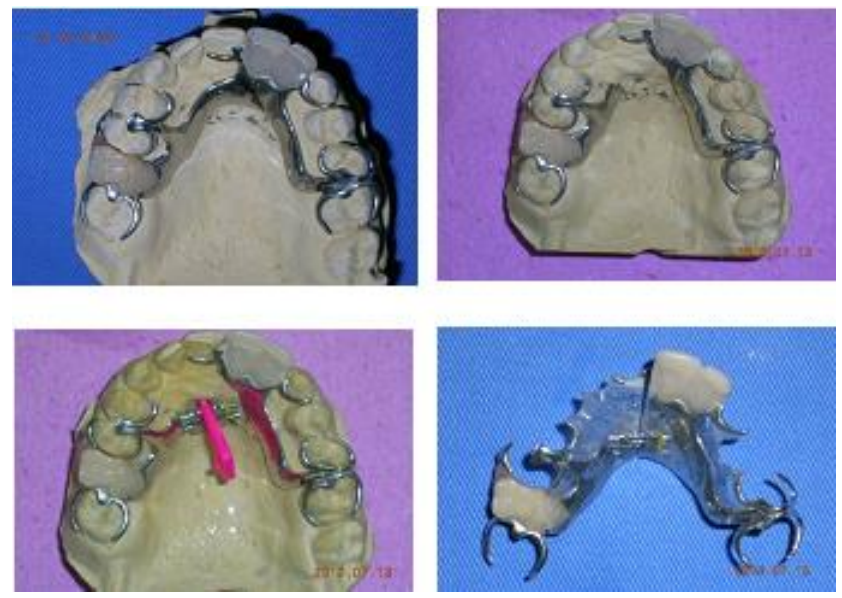

Figura 6: Confecção da PPT, com inclusão do torno expansor.

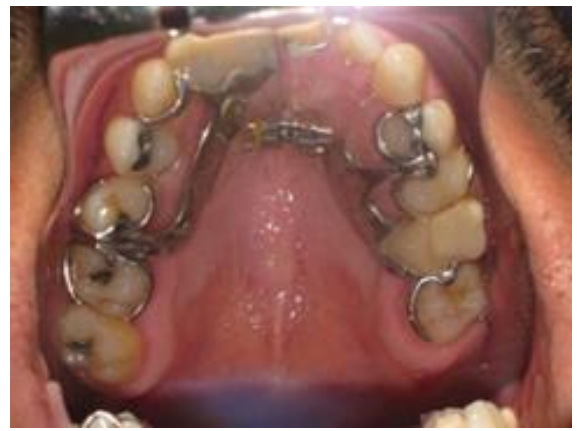

Figura 7: Foto intrabucal, com a PPR adaptada em posição.

As ativações inicialmente ocorreram durante as consultas mensais, com $1 / 4$ de volta. Após a adaptação do paciente, foi orientado sua ativação com $1 / 4$ de volta quinzenalmente, com acompanhamento mensal pelo ortodontista. Durante o tratamento houve a necessidade de realizar reembasamentos da PPR. Essa mecânica foi aplicada durante 10 meses.

No final do tratamento ortodôntico, notou-se a presença de diastemas em razão da movimentação dentária, expansão e harmonização do formato do arco superior. Em seguida, após instalação do aparelho fixo, houve o fechamento diastemas, alinhamento dos dentes, nivelamento da linha média. Ademais, possibilitou contemplar o espaçamento solicitado pelo implantodontista (Figuras 8 a 10).

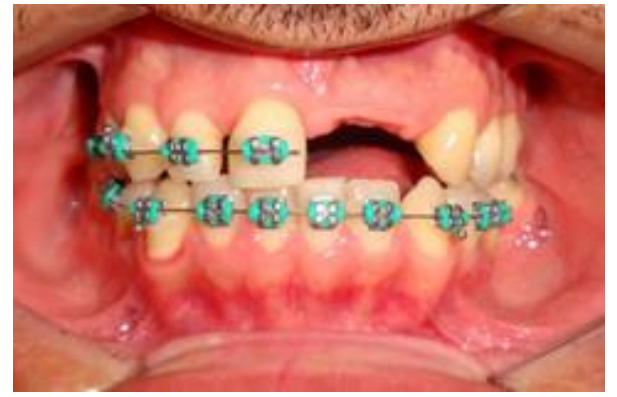

Figura 8: Foto intrabucal frontal após colagem dos braquetes.

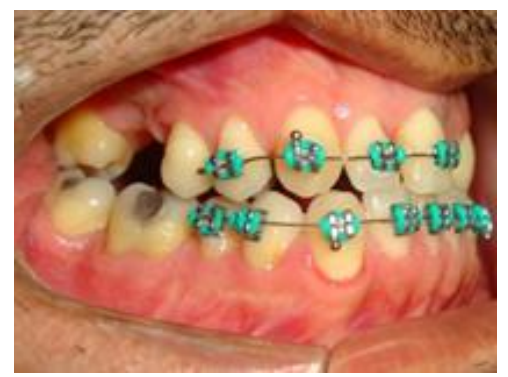

Figura 9: Foto intrabucal lateral direita após colagem dos braquetes.

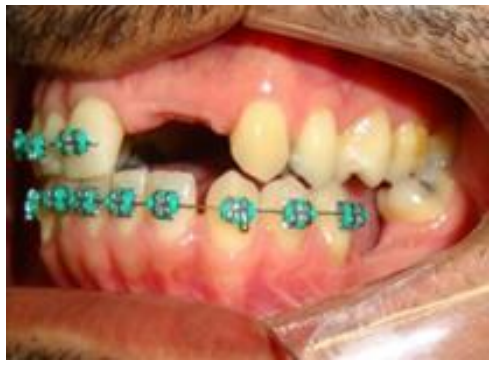

Figura 10: Foto intrabucal lateral esquerda após colagem dos braquetes.

Observa-se nas Figuras 11 a 13 que os espaços inicialmente edentulos, região dos dentes 16, 21, 22 e 36 foram reabilitados com implantes e coroas protéticas. Nota-se a presença da linha média nivelada, harmonia oclusal e devolução da estética e função do sistema estomatognático. Algumas limitações de posições dentárias ainda permaneceram, contudo isto foi previsível, em razão da intervenção ortodôntica ter sido realizada seguindo aos pedidos do implantodontista, com anuência do paciente.
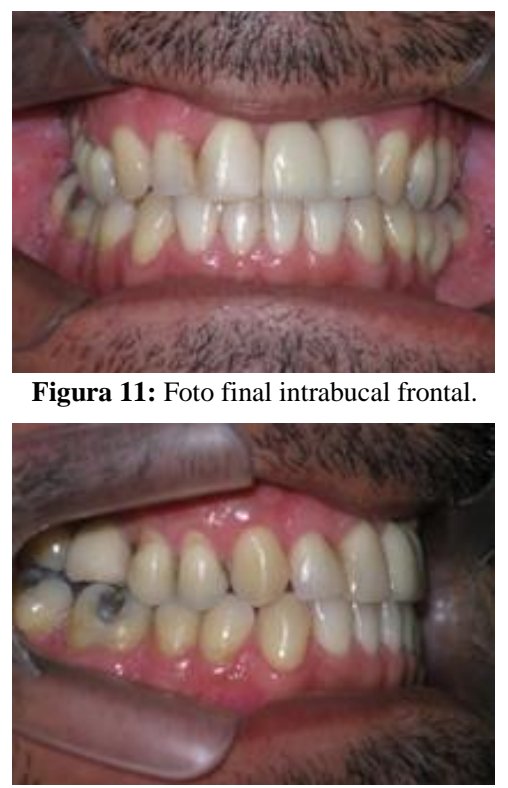

Figura 12: Foto final intrabucal lateral direita

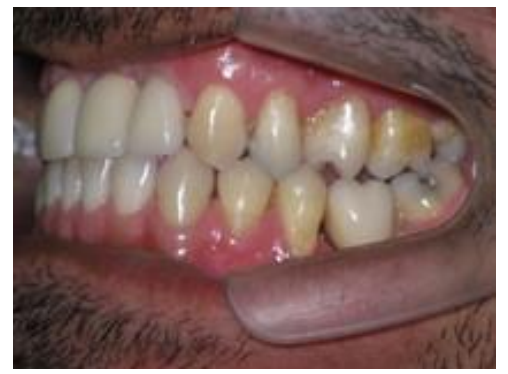

Figura 13: Foto final intrabucal lateral esquerda. 


\section{- Caso Clínico 2}

Paciente do sexo feminino, 54 anos, procurou o tratamento ortodôntico por indicação do implantodontista para correção da má oclusão e posteriormente, espaçamento das regiões a serem reabilitadas. Pelo exame clínico diagnosticou-se a presença da mordida cruzada posterior esquelética unilateral do lado direito, assimetria intra-arco superior, dentes 25 e 45 giro vertidos, e molares inferiores inclinados (mesial). Notou-se a ausência dos dentes 12 e 35, e a presença de várias regiões com perdas ósseas em razão dos traumas oclusais, nos seguimentos anteriores e posteriores do arco superior. Além disso, há presença de várias restaurações extensas em resina composta e amalgama. A paciente compareceu à consulta utilizando uma PPR superior provisória, reabilitando a região do dente 22. Dessa forma, foi utilizada essa mesma prótese para a inclusão de torno expansor e retentor de palatino com resina acrílica. A mecânica instituída foi baseada nos princípios biológicos da filosofia de bioprogressiva. Como protocolo para o uso, as ativações inicialmente foram de $1 / 4$ de volta pelo ortodontista, e posteriormente pela paciente semanalmente (Figuras 14 a 18).

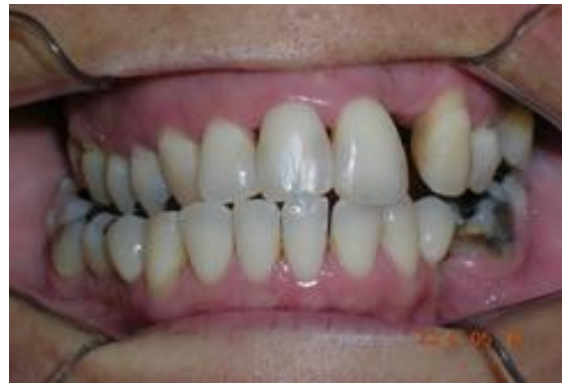

Figura 14: Foto inicial intrabucal frontal.

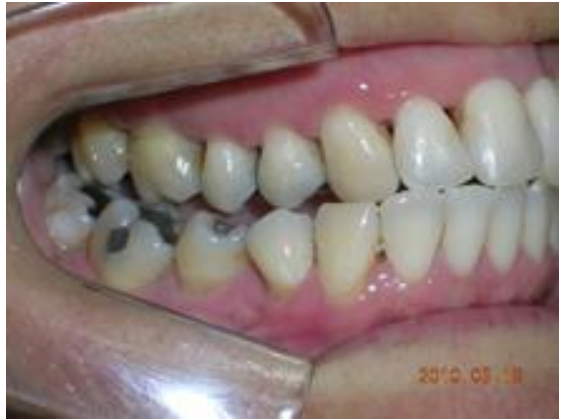

Figura 15: Foto inicial intrabucal lateral direita.

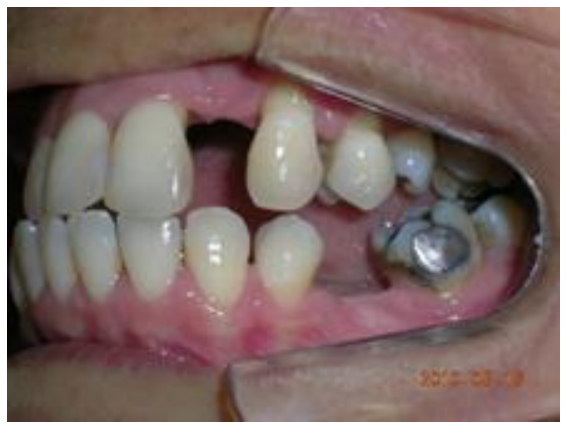

Figura 16: Foto inicial intrabucal lateral esquerda

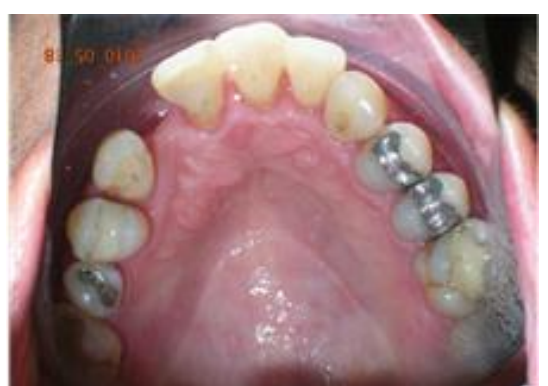

Figura 17: Foto inicial oclusal superior.

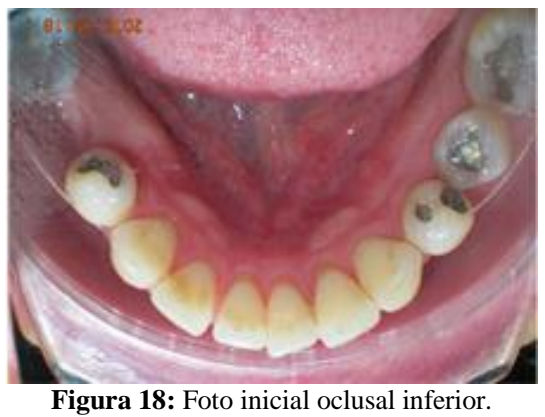

Após 4 meses de tratamento, houve o descruzamento da mordida cruzada, expansão e melhor conformação da parábola do arco superior. $\mathrm{Na}$ figura 15, observa-se a colagem dos braquetes na região anterior superior. No arco inferior, houve a extração do dente 36 em razão do surgimento de lesão periapical, que opção, a paciente optou por extraí-lo (Figuras 19 a 21).

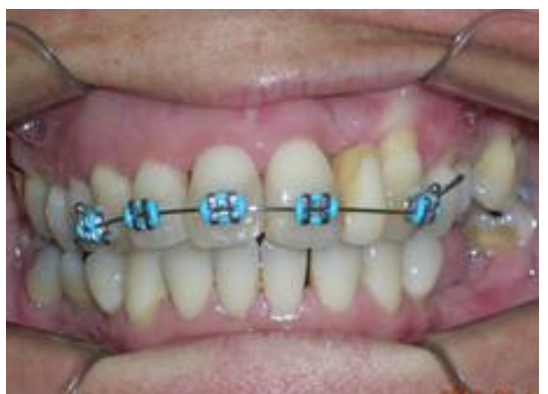

Figura 19: Foto intrabucal frontal após colagem dos braquetes.

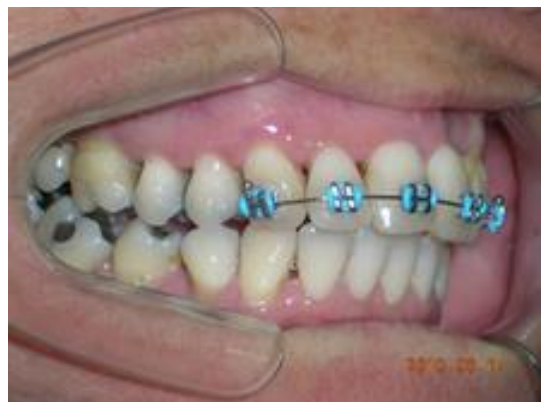

Figura 20: Foto intrabucal lateral direita após colagem dos braquetes.

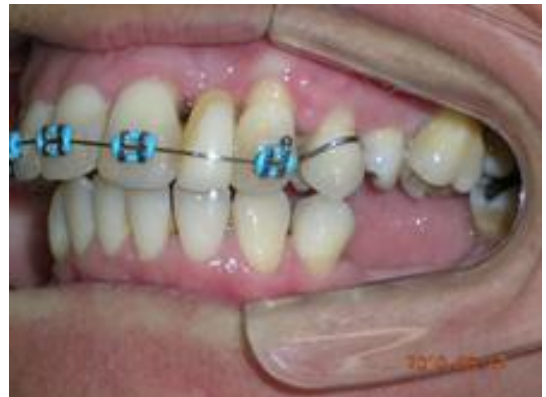

Figura 21: Foto intrabucal lateral esquerda após colagem dos braquetes. 
Nas Figuras 22 a 24, observa-se a ausência do dente 14, que devido a uma fratura radicular foi encaminhado para extração. Foi instalado no arco superior a barra palatina para ancoragem dos molares, inseridos fio twist-flex do dente 16 ao 23 , e sobreposto com fio de aço 0,16 do dente 12 ao 23 . Foi feita a distalização do dente 13 com fio elástico de seda, saindo do braquete do canino ao tubo do dente 16. No arco inferior, foi instalado o Arco Base Inferior para intrusão dos incisivos, verticalização do molar e nivelamento da curva de Spee. Este dispositivo foi confeccionado com fio de cromocobalto Elgiloy azul 0,016 " x 0,016 .

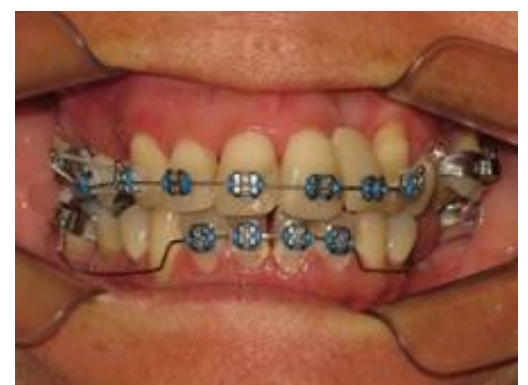

Figura 22: Foto intrabucal frontal - uso do Arco Base Inferior.

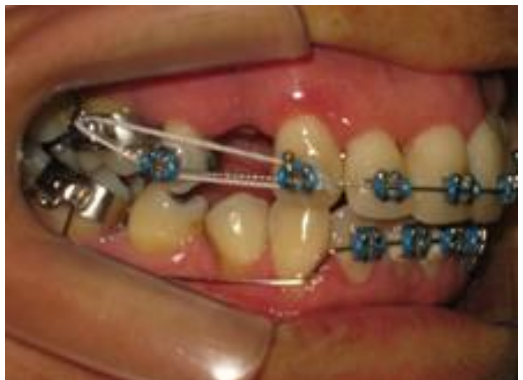

Figura 23: Foto intrabucal lateral direita - uso do Arco Base Inferior.

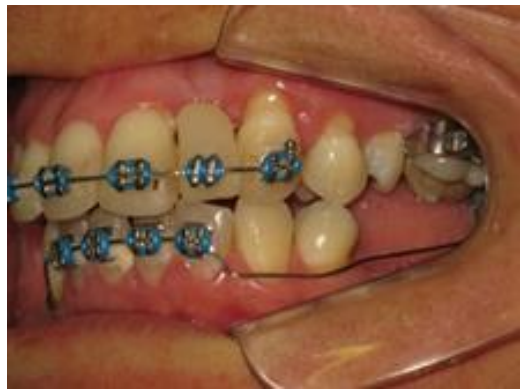

Figura 24: Foto intrabucal lateral esquerda - uso do Arco Base Inferior.

Após tracionar o canino superior direito em chave de oclusão, houve a mesialização do setor posterior, para compensação e fechamento do espaço exclusivamente pela ortodontia. Por tratar-se de uma paciente em faixa etária avançada, o uso de forças para movimentações dentárias devem ser leves e restritas para se obter o melhor resultado biológico sem efeitos colaterais. No arco inferior, após o uso do Arco Base Inferior, foram feitos os alinhamentos e nivelamentos necessários. Nota-se nas Figuras 25 a 27, que após a finalização do tratamento ortodôntico, houve a correção da má oclusão do sentido transversal, melhor disposição dentaria e harmonização interoclusal. Os implantes foram instalados nas regiões dos dentes 22, 35 e 36, bem como confeccionadas coroas provisórias. Por fim, ressalta-se que a intervenção ortodôntica do presente caso foi finalizada em decorrência do pedido do implantodontista, baseada nas expectativas do paciente e no planejamento inicial proposto e discutido pela equipe interdisciplinar.

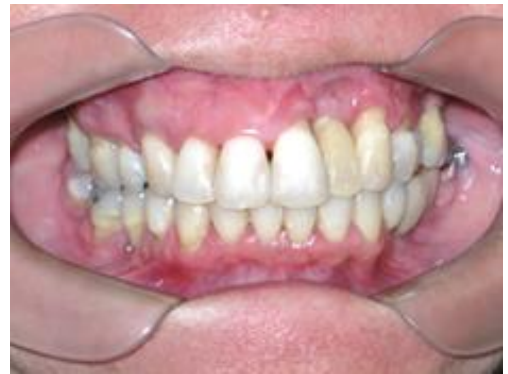

Figura 25: Foto final intrabucal frontal.

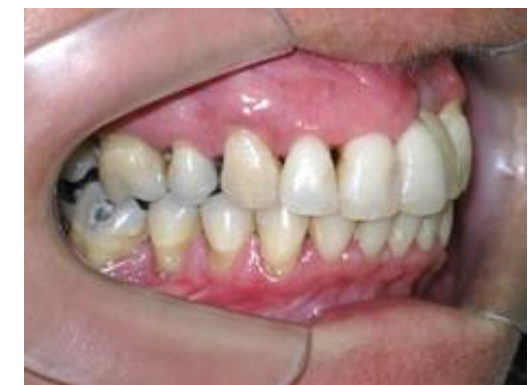

Figura 26: Foto final intrabucal lateral direita.

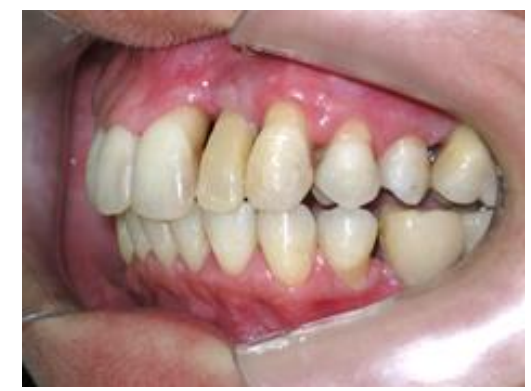

Figura 27: Foto final intrabucal lateral esquerda DISCUSSÃO

Com o presente estudo, foi possível relatar a importância do tratamento ortodôntico prévio à reabilitação oral do paciente, que além da devolução da estética dental, possibilitou a regularização do plano oclusal e de todo o sistema estomatognático dos pacientes. Ressalta-se neste contexto, a necessidade do planejamento do caso clínico, em conjunto pelos profissionais ortodontista/implantodontista/protesista, a fim de se ponderar as limitações, vantagens e custos-benefícios que as intervenções podem ter sobre os objetivos do tratamento e as expectativas do paciente ${ }^{8,12}$.

Nos casos clínicos apresentados, em razão das várias ausências dentárias, foram planejadas as inclusões de tornos expansores nas PPRs retentores palatinos em resina acrílica. Isso possibilitou a movimentação dentária vestíbulo-lingual do arco superior e a abertura de diastemas, que consequentemente, ampliou o arco superior e gerou o espaço necessário para a instalação do implante e 
peça protética. Nas duas situações clínicas relatadas, não haveria a possibilidade de uma intervenção exclusivamente ortodôntica para o fechamento de diastema, pelo tracionamento dos dentes adjacentes. Contudo, há uma grande discussão acerca do uso exclusivo da ortodontia ou a instalação de implantes quando há ausência de incisivos centrais ou lateais.

Rosa et al. ${ }^{13}$, em seu estudo, considerou que o tratamento exclusivamente ortodôntico pra fechamento de diastemas por agenesia de incisivos laterais superiores na adolescência, torna-se vantajosa, em razão da identificação da ausência ser diagnosticada nesta fase etária, onde é possível instalação do aparelho ortodôntico fixo, em contraponto ao implante, que deverá ser postergada até a maturação do crescimento e desenvolvimento do indivíduo. Além disso, o autor ressalta a possibilidade de obter-se contornos gengivais mais naturais, consignação dos espaços e ameias interdentais, bem como menor gasto com investimentos ${ }^{13}$.

Em relação à abordagem implantodontica, Cruz et al. ${ }^{14}$ avaliaram em sua revisão de literatura, as possibilidades indicativas de pilares metálicos ou cerâmicas na região anterior de maxila. Para tanto, deve-se levar em consideração que os intermediários possuam contornos, inclinações, cor e propriedades óticas semelhantes aos dentes naturais. Dessa forma, o autor conclui que os pilares metálicos são os mais indicados em razão das vantagens funcionais e estéticas ${ }^{14}$.

Neste contexto, outro fator a ser considerado no planejamento, é a escolhe do tipo de material e o protocolo restaurador que será instituído. Terra et al. ${ }^{15}$ ressaltam que próteses metal-free sobre são ótimas indicações para regiões anteriores, com designação sobre implantes osseointegrados. $\mathrm{O}$ uso deste sistema torna-se atrativo em razão da excelência estética, biocompatibilidade, resistência mecânica e a degradação e passível de cimentação adesiva e convencional ${ }^{15}$.

Por trata-se de intervenções ortodônticas em pacientes adultos/idosos, assim como relatado nos casos clínicos do presente estudo, variáveis como ausência dentaria, uso de peças protéticas fixas e removíveis e periodontopatias ${ }^{16,17}$, limitam o uso de recursos ortodônticos nestas populações. Neste contexto, a filosofia bioprogressiva de Ricketts tornase indicada, em razão da possibilidade da individualização do tratamento, que baseada nas limitações e expectativas do paciente, é elaborado um plano de tratamento personalizado às suas necessidades. Além disso, a filosofia bioprogressiva, por utilizar fios ortodônticos condizentes com movimentos biológicos, controlados e segmentados, possibilita intervenções mais eficientes, seguras e livre de agressões fisiológicas ${ }^{10,11}$.

Em um estudo conduzido por Garbin et al ${ }^{18}$. foi possível ressaltar a relevância do recurso elucidado por Ricketts, denominado Visualização dos Objetivos do Tratamento. Trata-se de uma metodologia empregada, a fim de evitar improvisos e empecilhos durante o tratamento ortodôntico. Essa previsibilidade garante otimizar o tratamento, evitar erros e improvisos, informar ao paciente sobre as possíveis limitações do tratamento em razão da severidade da má oclusão, e subsidiar o planejamento ortodôntico do caso, quando em atuação com equipe multidisciplinar ${ }^{18}$.

Pelizzari et al. ${ }^{9}$ ressaltam que as potencialidades do tratamento ortodôntico devem ser discutidas com as especialidades que posteriormente atuarão no tratamento do paciente, para que sejam esclarecida suas limitações e vantagens. O autor perfaz, que os movimentos ortodônticos prévios a reabilitação oral do paciente, possibilita evitar desgastes dentários desnecessários, corrigir as posições oclusais e as distribuição das forças dissipantes da mastigação, e preservar estrutura dental, periodontal e articular do paciente? .

Almeida et al. ${ }^{19}$ relataram em seu estudo que movimentos de abertura ou fechamento de diastemas, verticalização de molares, e reposicionamento dos dentes pilares são os principais interesses ortodônticos antes do tratamento reabilitar oral. Além disso, ressaltou-se que com essas intervenções, o tratamento torna-se mais conservador, diminuindo os riscos de envolvimento endodôntico, periodontais e restauradores ${ }^{19}$.

Alfallaj $^{12}$ relata que as intervenções ortodônticas pré protéticas são aplicáveis às várias situações clinicas, principalmente na correção de dentes mal posicionados, extrusão dentaria para aumento de coroa clínica e correção do contorno gengival e processo alveolar, intrusão dentária para correção de sobremordida e nivelamento oclusal, e inclinação/verticalização de molares ${ }^{12}$.

Em relação à viabilidade da abordagem ortodôntica em pacientes adultos idosos, a idade não é um fator de elegibilidade, mas condições adaptativas devem ser implementadas, como movimentos dentários leves; objetivos restritos; avaliação da condição sistêmica do paciente; qualidade das bases ósseas; queixa do paciente e motivação ao tratamento. $\mathrm{O}$ esclarecimento das limitações e planejamento do caso clínico de maneira franca e motivadora, tornam o tratamento satisfatório para ambos os interesses ${ }^{20}$.

$\mathrm{O}$ uso do torno expansor e estrutura palatina em resina acrílica foram associadas as estruturas da próteses parciais removíveis que os pacientes já faziam uso, na intenção de propiciar a correção da mordida cruzada presente em todos os casos clínicos, bem como possibilitar melhor conformação do arco superior. O uso desses artifícios ortodônticos foram essências em todos os casos, pois dada a ausência da 
vários elementos dentários, principalmente molares, seria dificultado o uso de expansores dentoalveolares dentosuportadadas. Além disso, como os pacientes já faziam uso de estruturas protéticas removíveis, ficaria impossibilitada a instalação de outros recursos ortodônticos na região do palato. Ressalta-se também, que esta abordagem pré-protética é uma opção financeiramente vantajosa para o paciente, pois a mecânica instituída para a intervenção ortodôntica é adaptada sobre a peça protética já em uso.

$\mathrm{O}$ arco base ou arco utilidade de Ricketts, conforme empregado neste estudo, evidencia a versatilidade das suas funções, em razão das suas variadas indicações e possibilidades clínicas, como em considerações pré-protéticas ${ }^{21}$. Confeccionado com fio de liga cromo-cobalto (elgiloy), atua com forças dissipantes e controladas, gerando movimentos de intrusão, extrusão, avanço, retração, torque, giro, ancoragem, expansão, retração e manutenção do espaço $^{22,23}$. O uso dos recursos mecanoterapêuticos da filosofia bioprogressiva de Ricketts torna-se vantajosa e eletiva nas intervenções pré protéticas, em razão da individualização do tratamento, previsibilidade do prognóstico pela Visualização dos Objetivos do Tratamento, aplicação de forças leves e biológicas, uso de arcos seccionados, maior controle de torque e ancoragem ${ }^{18,24,25}$.

\section{CONCLUSÃO}

Conclui-se que a bioprogressiva de Ricketts no tratamento prévio à reabilitação oral mostrou-se eficaz e indicativa. Além disso, ressalta-se que o tratamento ortodôntico pré-protético é de grande relevância para a devolução da estética e função do sistema estomatognático. Para tanto, deve-se levar em consideração a necessidade de um minucioso planejamento e individualização do caso, para se obter maior qualidade no tratamento, e assim garantir melhores resultados de estabilidade pós-tratamento.

\section{REFERÊNCIAS}

1. Melo M, Ata-Ali J, Ata-Ali F, Bulsei M, Grella P, Cobo T, Martínez-González JM. Evaluation of the maxillary midline, curve of the upper lip, smile line and tooth shape: a prospective study of 140 Caucasian patients. BMC Oral Health. 2020 Feb 6;20(1):42.

2. Delalíbera HVC, Silva MC, Pascotto RC, Terada HH, Terada RSS. Avaliação estética de pacientes submetidos a tratamento ortodôntico. Acta Sci Health Sci. 2010;32(1):93-100.

3. Vargas AMD, Paixão HH. Perda dentária e seu significado na qualidade de via de adultos usuários de serviço público de saúde bucal do Centro de Boa Vista, em Belo Horizonte. Cienc saude coletiva. 2005; 10(4):1015-1024.

4. Perin L, Brondani LP, Studzinki C, Barbon FJ, Casalli JL. Análise da percepção da estética do sorriso entre cirurgiões dentistas de diferentes especialidades. Full Dent. Sci. 2018;9(36):111-16.

5. Al-Johany SS, Alqahtani AS, Alqahtani FY, Alzahrani AH. Evaluation of different esthetic smile criteria. Int J Prosthodont. 2011 JanFeb;24(1):64-70. Erratum in: Int J Prosthodont. 2011;24(2):103.

6. Câmara CA. Estética em ortodontia: seis linhas horizontaisdo sorriso. Dental Press J Orthod. 2010; 15(1):118-31

7. Ferrando-Magraner E, García-Sanz V, BellotArcís C, Montiel-Company JM, Almerich-Silla JM, Paredes-Gallardo V. Oral health-related quality of life of adolescents after orthodontic treatment. A systematic review. J Clin Exp Dent. 2019;11(2):e194-e202.

8. Pedroso JF, Lima DR, Lima FR, Panizato R. Multidisciplinary treatment: association among orthodontics, implantodontia and prosthetics. Case report. Braz Dent Sci. 2018;21(3):357-63.

9. Pelizzari D, Dallanora LJ, Rebelato C, Varela RF, Luthi LF. Reabilitação protética auxiliada por técnicas de mo- vimentação ortodôntica - revisão de literatura. ACBS U\&C. 2012;3(1):95-104

10. Garbin AJI, Grieco FAD, Rossi LB. Ortodontia de visão. Ribeirão Preto: Editora Tota; 2016.

11. Garbin AJI, Wakayama B, Teruel GP. Tratamento da classe II divisão 1 - uma abordagem terapêutica com a mecânica bioprogressiva e arco seccionado de forças paralelas. Rev. UNINGÁ, 2019;56(S3):71-83.

12. Alfallaj H. Pre-prosthetic orthodontics. Saudi Dent J. 2020;32(1):7-14.

13. Rosa M, Zachrisson BU, Integração da Ortodontia (Fechamento de Espaço) e da Odontologia Estética no Tratamento de Pacientes com Agenesia de Incisivos Laterais Superiores. R Clin Ortodon Dental Press. 2002;1(1):41-55.

14. Cruz FLG, Reis JRG, Teixeira VCF, Vieira ID, Ribeiro CG, ASSIS, NMSP. Implantodontia estética na região anterior da maxila - pilar metálico ou cerâmico? Uma revisão da literatura. Rev Bras Implant. 2010;17(1):8-11.

15. Terra GTC, Domingos VBTC. Prótese livre de metal sobre implante. J Biodentistry Biomater. 2011;1:68-75.

16. Fernandes-Costa A, Vasconcelos M, Queiroz L, Barboza C, Vasconcelos R. As principais modificações orais que ocorrem durante $\mathrm{O}$ envelhecimento. Rev Bras Ciênc Saúde. 2013;17(3):293-300.

17. Meira IA, Martins ML, Maciel PP, Cavalcanti YW, Araújo TP, Piagge CSLD. Multidisciplinaridade no cuidado e atenção à saúde bucal do idoso. Rev Ciênc Med. 2018;27(1):39-45.

18. Garbin AJI, Wakayama B, Martin IM. Filosofia Bioprogressiva de Ricketts e Arco Seccionado de 
Forças Paralelas no tratamento da Classe II: relato de caso. Arch Health Invest. 2020;9(1):49-54.

19. Almeida RR, Bonfante G, Neto GI, Almeida MR. A inter-relação ortodontia e prótese: apresentação de um caso clínico. R Dental Press Ortodon Ortop Facial 1997; 4:13-9.

20. Valle-Corotti KM, Valle CVM, Neves LS, Henriques JFC, PInzan A. A ortodontia na atuação odontogeriátrica. Rev Dent Press Ortodon Ortop Facial. 2008; 13(2):84-93.

21. Claro CAA, Abraão J, Reis SAB, Laganá DC. Stress distribution in a photoelastic model resulting from intrusion of mandibular incisors using Ricketts utility arch. Dental Press J Orthod. 2011 Sept-Oct;16(5):89-97.

22. Figueiredo MA, Figueiredo CTP, Nobuyasu M, Gondo GY, Siqueira DF. A versatilidade clínica do arco utilidade. R Dental Press Ortodon Ortop Facial 2008;13(4):127-56.

23. Aranha MF, Garbin AJI, Grieco FAD, Guedes Pinto E, Mendonça MR. Utilização dos arcos seccionados para o tratamento da má oclusão classe II, divisão 2. Rev clín ortodon Dental Press. 2010;9(3):51-6.

24. Lemos RT, Mahmound RH, Grieco FAD, Garbin AJI, Guedes-Pinto E. Tratamento da má oclusão de Classe II segundo a terapia bioprogressiva: relato de caso clínico. Rev clín ortodon Dental Press. 2009;8(3):82-9.

25. Sahad MG, Grieco FAD, Cartaxo ZBP, Guedes Pinto E, Prokopowitsch I, Toshie A. Tratamento da má oclusão de Classe II, subdivisão direita, segundo a terapia bioprogressiva. Rev clín ortodon Dental Press. 2012; 11(1):92-7.

\section{CONFLITO DE INTERESSES}

Os autores declaram não haver conflitos de interesse

\section{AUTOR PARA CORRESPONDENNCIA}

\section{Bruno Wakayama}

Faculdade de Odontologia de Araçatuba FOA/UNESP.

Rua José Bonifácio, 1193 - Vila Mendonça 16015050 Araçatuba/SP

E-mail: brunowakayama@gmail.com 